electrically excitable tissue, including neurones. This may be a dosedependent phenomenon, however, the patient usually presenting with the more typical neurological features before a sufficiently toxic concentration is achieved. Additionally the brain of the elderly or "arteriosclerotic" patient may possibly be predisposed to the development of digoxin-induced convulsions; the previous case report described a 72-year-old man.

Transient cerebral ischaemic episodes may, therefore, only partially account for the blackouts seen in elderly patients taking digoxin, and we recommend that, even when there is no gross disturbance of cardiac rhythm, the serum digoxin concentration be measured to exclude digoxin neurotoxicity.

${ }^{1}$ Goodman LS, Gilman (eds) A. Digitalis and allied cardiac glycosides. In: The pharmacological basis of therapeutics. 5th ed. New York: Macmillan Publishing Co, 1975:653-82.

${ }^{2}$ Douglas EF, White PT, Nelson JW. Three per second spike-wave in digitalis toxicity. Arch Neurol $1971 ; 25: 373-5$.

${ }^{3}$ Lely AH, van Enter CHJ. Non-cardiac symptoms of digitalis intoxication. Am Heart f 1972;83:149-52.

1 Sarangi A, Tripathy N, Lall D, Patnaik BC, Swain AK. Study of serum digoxin status in digitoxicity by radioimmunoassay. Am Heart $\mathcal{f} 1980$ 99:289-93.

${ }^{5}$ Bertler A, Anderson KE, Wethrell G. Concentration of digoxin in choroid plexus. Lancet 1973;ii:1453.

(Accepted 15 September 1981)

Department of Materia Medica, University of Glasgow, Stobhill General Hospital, Glasgow G21 3UW

D J KERR, $\mathrm{MB}$, $\mathrm{CHB}$, house physician (present appointment: senior house officer in medicine, Western Infirmary, Glasgow)

H L ELLIOTT, MB, MRCP, lecturer

W S HILLIS, MB, FRCP, senior lecturer

\section{"Home brew" compared with commercial preparation for enteral feeding}

Enteral feeding is the most appropriate route for administering protein and energy to malnourished patients when the gastrointestinal tract is capable of normal absorption.' The enteral route is safer and considerably cheaper than total parenteral nutrition. ${ }^{2}$ Enteral feeding is well tolerated provided it can be delivered by continuous slow nasogastric or nasoduodenal infusion, thereby avoiding the problems of hyperosmolar diarrhoea and the reluctance by some convalescent patients to take a liquid diet by mouth. Commercially available enteral solutions are expensive, however, and it has been argued that a liquid diet of similar protein and energy content can be prepared by most diet kitchens. We compared a blenderised diet based on milk albumaid hydrolysate, Caloreen, and Prosparol ("home brew") with a commercially available enteral preparation containing the same protein and calorie content (Isocal) in 28 patients requiring nutritional treatment after major gastrointestinal surgery. Method of treatment was determined by numbered randomisation cards.

\section{Patients, methods, and results}

Any patient unable or unwilling to take nutrients by mouth after a major gastrointestinal operation associated with complications was admitted to the study. Patients who required jejunostomy feeds or intermittent positive pressure ventilation were excluded. Indications for feeding included: gastrectomy complicated by wound dehiscence; abscess or a duodenal fistula ( $: 8)$; reconstructive gastric operations in patients malnourished before operation $(n-10)$; resection for colorectal carcinoma complicated by fistula or abscess $(n-6)$; and resection for inflammatory bowel disease associated with intra-abdominal sepsis $(n=4)$. Nutritional treatment was given for at least seven days by fine-bore nasogastric tube positioned under radiographic control. During the first 48 hours the tube feed was diluted and administered at increasing volume until the patient was able to tolerate the full strength solution at a rate of $125 \mathrm{ml}$ per hour. ${ }^{3}$ Fifteen patients received Isocal and 13 the "home brew" (table). Diarrhoea occurred in nine patients, two after Isocal, but one had antibiotic-associated colitis and the other a pelvic abscess. Two of the seven patients with diarrhoea receiving the "home brew" had a pelvic abscess but in the remaining five patients the intestinal disturbance was so severe that the enteral feeding had to be discontinued.
Comparison of commercial feed and "Home Brew" enteral feeding

\begin{tabular}{lcc}
\hline & $\begin{array}{c}\text { Commercial feed } \\
(\text { Isocal }) \\
(\mathrm{n}=15)\end{array}$ & $\begin{array}{c}\text { "Home brew" } \\
(\mathrm{n}=13)\end{array}$ \\
\hline $\begin{array}{l}\text { Severe diarrhoea } \\
\text { Pelvic abscess } \\
\text { Antibiotic associated colitis }\end{array}$ & $\begin{array}{c}2 \\
7\end{array}$ \\
$\begin{array}{l}\text { Infected solution } \\
\text { No cause identified }\end{array}$ & 1 & 2 \\
Obstructed fine bore tube & & 4 \\
\hline
\end{tabular}

Cultures of the solutions in these patients yielded yeasts in three and Staphylococcus aureus in one. Intermittent obstruction of the fine-bore tube was a problem in six patients who were given the "home brew" but in none receiving Isocal.

\section{Comment}

Our observations cast doubt on the safety and efficacy of liquid diets prepared in hospital. Contamination by yeasts and staphylococcus occurred at weekends when the materials had been prepared earlier and stored on the wards. Fine-bore feeding tubes often became obstructed by the locally prepared solutions and in some patients the fine-bore tube had to be replaced by a conventional nasogastric tube, which was unpleasant for the patients. The study was discontinued because the nurses found the locally prepared solutions difficult to administer at a constant rate of infusion, and because of the risks of infection observed in the study. We believe, therefore, that commercially available liquid diets are safer and easier to handle if fine-bore enteral feeding is to be used for patients requiring nutritional support after major gastrointestinal operations.

\footnotetext{
1 Russell RI. Elemental diets. Gut 1975;16:68-79.

2 Blackett RL, Bakran A, Bradley LA, Halsall A, Hill GL, McMahon MJ A prospective study of subclavian vein catheters used exclusively for the purpose of intravenous feeding. Br F Surg 1978;65:393-5.

${ }^{3}$ Sagar S, Harland $\mathrm{P}$, Shields R. Early postoperative feeding with elemental diet. Br Med f 1979;i:293-5.
}

(Accepted 6 October 1981)

The General Hospital, Birmingham B4 6NH

M R B KEIGHLEY, Ms, FRCS, consultant surgeon/reader in surgery BARBARA MOGG, AIMS, research technician SANDRA BENTLEY, SRN, research nurse CAROLINE ALLAN, SRN, ward siste

\section{Gastrointestinal haemorrhage and benoxaprofen}

Benoxaprofen is a non-steroidal anti-inflammatory agent similar to naproxen and ibuprofen but which has a lower incidence of gastrointestinal disturbance ${ }^{1}$ and produces less gastric microbleeding. ${ }^{2}$ During three months three patients who had been receiving benoxaprofen were admitted to a general medical unit with gastrointestinal haemorrhage associated with peptic ulceration.

\section{Case reports}

Case 1-A 76-year-old woman was admitted three weeks after starting benoxaprofen $600 \mathrm{mg}$ daily for osteoarthritis, mainly in her right leg. She had no past history of dyspepsia and no family history of peptic ulceration. Within a week of taking the drug she began to feel nauseated and on the day of admission had a large haematemesis. She was seriously ill and the haemoglobin concentration was $8.0 \mathrm{~g} / \mathrm{dl}$. Endoscopy showed multiple ulcers in the duodenum and a large gastric ulcer. Despite resuscitative measures, including blood transfusion, she deteriorated further; abdominal films showed pneumoperitoneum. At an emergency operation the duodenal ulcer was seen to have perforated and the peritoneal cavity contained 21 of bile-stained fluid. The perforation was sealed but she failed to improve and died on the eighth postoperative day.

Case 2-A 76-year-old woman was admitted six weeks after starting benoxaprofen $600 \mathrm{mg}$ daily for osteoarthritis. She had no past history of dyspepsia. Within two weeks of taking the drug she complained of nausea 
and epigastric pain. After a month she stopped taking the drug and two weeks later was admitted as an emergency case because of several haematemeses and melaena stools. On admission her haemoglobin concentration was $5 \cdot 0 \mathrm{~g} / \mathrm{dl}$. Endoscopy showed a large duodenal and a gastric ulcer. She improved after a blood transfusion but then deteriorated; abdominal films showed free gas in the peritoneum. Emergency surgery disclosed perforation by the duodenal ulcer and also stercoral perforation of the sigmoid colon. The perforated duodenal ulcer was oversewn and a left hemicolectomy performed; she made a slow but satisfactory recovery.

Case 3-A 78-year-old woman had a duodenal ulcer confirmed by barium meal in 1966 but had had no further dyspeptic symptoms until she started taking benoxaprofen $600 \mathrm{mg}$ daily for osteoarthritic pain in her right knee. After one month she complained of gnawing epigastric pain associated with nausea but no vomiting. She stopped taking benoxaprofen two weeks later. Three days after stopping the drug she passed several melaena stools and became dizzy and faint. On admission her haemoglobin concentration was $9.7 \mathrm{~g} / \mathrm{dl}$. She was transfused with 4 units of packed cells and endoscopy showed two active duodenal ulcers. Cimetidine was prescribed, her stools became negative for occult blood, and she was discharged.

\section{Comment}

The incidence of peptic ulceration in patients taking benoxaprofen is about $0.4 \%,{ }^{1}$ with only one case of gastrointestinal haemorrhage occurring four months after the drug had been discontinued. The incidence of gastrointestinal disturbance may be low because benoxaprofen is a relatively weak inhibitor of prostaglandin synthetase. ${ }^{3}$ Gastrointestinal haemorrhage in the three patients described here may have been unrelated to benoxaprofen. Nevertheless, the timing strongly suggests that the development of peptic ulceration was associated with the administration of benoxaprofen at the recommended daily dosage. The assertion that benoxaprofen is less likely to cause serious gastrointestinal disturbance than other non-steroidal antiinflammatory agents ${ }^{4}$ requires further evaluation, especially in the elderly.

I am grateful to Drs R J Kellett, J F Munro, and J Nimmo for permission to describe patients admitted under their care. I also thank Dr J F Munro for constructive comments on the manuscript and Mrs J Troup for secretarial work.

${ }^{1}$ Mikulaschek WM. Long term safety of benoxaprofen. 7 Rheumatol 1980; 7,suppl 6:100-7.

${ }^{2}$ Ridolfo AS, Crabtree RE, Johnson DW, Rockhold FW. Gastrointestinal microbleeding: comparisons between benoxaprofen and other nonsteroidal anti-inflammatory agents. 7 Rheumatol $1980 ; 7$,suppl 6:36-47.

${ }^{3}$ Cashin CH, Dawson W, Kitchin EA. The pharmacology of benoxaprofen. f Pharm Pharmacol 1977;29:330-6.

4 Alarcon-Segovra D. Long term treatment of symptomatic osteoarthritis with benoxaprofen. Double-blind comparison with aspirin and ibuprofen. F Rheumatol 1980;7,suppl 6:89-99.

(Accepted 12 October 1981)

\section{Eastern General Hospital, Edinburgh EH6 7LN}

I C STEWART, MB, MRCP, senior house officer (now registrar in respiratory medicine, City Hospital, Edinburgh EH10 5SB)

\section{Immune response of infants in tropics to injectable polio vaccine}

As a result of two decades of experience with oral polio vaccine (OPV, Sabin) in India, certain problems have come to light. ${ }^{1}$ When it is used in the conventional manner, the protective efficacy of oral polio vaccine is only moderate and vaccine failure is common. ${ }^{2}$ To improve efficacy, a five-dose schedule for primary immunisation has been recommended, but this is out of step with the diphtheria, pertussis, and tetanus vaccination, for which only three doses are sufficient. ${ }^{3}$ Injectable polio vaccine (IPV, Salk) is, however, available as an alternative vaccine, and it is important to evaluate its efficacy in developing countries. If found suitable its use may simplify routine immunisation of children as it can be combined with the diphtheria, pertussis, and tetanus vaccine into a quadruple vaccine and does not need to be frozen for long storage. We examined the immune response of infants given three doses of injectable polio vaccine incorporated with diphtheria, pertussis, and tetanus vaccine into a quadruple vaccine, as a first step in its evaluation in India.

\section{Patients, methods, and results}

Infants aged 6 to 45 weeks attending our immunisation clinic were given three doses of the quadruple vaccine. Each dose $(1 \mathrm{ml})$ contained 20, 2, and $3.5 \mathrm{D}$ antigen units of killed poliovirus types 1,2 , and 3 respectively, and was administered at four or eight weekly intervals to infants beginning their immunisation on alternate weeks. Blood was collected before the first dose and four weeks after the third dose by heel prick. The paired sera were simultaneously tested for the presence and titre of poliovirus-neutralising antibodies in steps of serial twofold dilutions starting from $1 / 8$ against 30 to 300 median tissue culture infective doses of each type of poliovirus, according to methods previously described. ${ }^{4}$

Out of 153 infants tested, 67 were seronegative to the three types of poliovirus before immunisation. The three doses were given at four-weekly intervals to 45 and at eight-weekly intervals to 21 . The table shows seroconversion rates.

Seroconversion in tritypic seronegative infants

\begin{tabular}{|c|c|c|c|c|c|}
\hline \multirow{2}{*}{$\begin{array}{c}\text { Interval } \\
\text { between } \\
\text { doses }\end{array}$} & \multirow{2}{*}{ No } & \multicolumn{3}{|c|}{ Seroconverted to poliovirus } & \multirow{2}{*}{$\begin{array}{c}\text { Sero- } \\
\text { conversion } \\
\text { index }(\%)\end{array}$} \\
\hline & & Type 1 & Type 2 & Type 3 & \\
\hline $\begin{array}{l}4 \text { weeks } \\
8 \text { weeks }\end{array}$ & $\begin{array}{l}45 \\
22\end{array}$ & $\begin{array}{l}45\left(1000^{\circ}\right) \\
22\left(100{ }_{0}^{\circ}\right)\end{array}$ & $\begin{array}{l}41(91 \cdot 1 \%) \\
22(100 \%)\end{array}$ & $\begin{array}{l}41(91 \cdot 1 \%) \\
21(95.5 \%)\end{array}$ & $\begin{array}{l}94 \cdot 1 \\
98 \cdot 5\end{array}$ \\
\hline Both groups & 67 & $67\left(1000_{u}^{\prime}\right)$ & $63(93.9 \%)$ & $62(92.5 \%)$ & $95 \cdot 5$ \\
\hline
\end{tabular}

Seroconversion to type 1 was complete in both groups. Response rates to types 2 and 3 were better in infants given the vaccine at eight-weekly intervals than in those given it at four-weekly intervals, but these differences were not statistically significant $(p>0.05)$. The overall response was $100 \%$ to type 1 and over $90 \%$ to types 2 and 3 . The seroconversion index, which is the mean response to the three types, was over $98 \%$ when injectable polio vaccine was administered at eight-weekly intervals.

\section{Comment}

Injectable polio vaccine is routinely used for infants and children in the Netherlands. The poliovirus antigen is formulated according to local needs and standards and contains relatively low levels of types 2 and 3. This is reflected in the seroresponse in our study. The response will probably improve further if the antigenic content of types 2 and 3 is enhanced.

This study suggests that the quadruple vaccine may be used in the routine immunisation of infants in developing countries, starting as early as 6 weeks of age, with better antibody response than with oral polio vaccine. ${ }^{1}$ The seroconversion index after three doses of injectable polio vaccine given at four-weekly intervals was $94.1 \%$ whereas it was only $78 \%$ after three doses of oral polio vaccine given under similar conditions. ${ }^{4}$ If injectable polio vaccine could be manufactured in sufficient quantities and at an economic price, it would be an effective alternative to oral polio vaccine in tropical countries.

We thank Dr Hans Cohen and Dr A L van Wezel of the Rijk's Institute, the Netherlands, for the supply of the vaccine, and Mrs Saroja Christopher and Mr P Vijayarathnam for technical help. This study was supported by the Indian Council of Medical Research.

${ }^{1}$ John TJ. Problems with oral poliovaccine in India. Indian Pediatr 1972;9: 252-5.

2 Ratnaswamy L, John TJ, Jadhav M. Paralytic poliomyelitis: clinical and virological studies. Indian Pediatr 1973;10:443-7.

3 John TJ. Antibody response of infants in tropics to five doses of oral poliovaccine. $\mathrm{Br}$ Med $\mathcal{F} 1976 ; \mathrm{i}: 811-2$.

4 John TJ, Devarajan LV, Luther L, Vijayarathnam P. Effect of breast feeding on seroresponse of infants to oral polio virus vaccination. Pediatrics 1976;57:47-53.

(Accepted 2 October 1981)

Department of Child Health and the Indian Council of Medical Research Centre of Advanced Research in Virology, Christian Medical College and Hospital, Vellore 632004, India

R KRISHNAN, MB, BS, DCH, registrar in child health

MALATI JADHAV, $\mathrm{MD}, \mathrm{DCH}$, professor of child health

R SELVAKUMAR, MVSC, senior research fellow in virology

T JACOB JOHN, FRCP, PHD, professor and head of Virology Centre 